\title{
Fluctuating asymmetry: a biological monitor of environmental and genomic stress
}

\author{
P. A. PARSONS \\ Waite Institute, University of Adelaide, Glen Osmond, SA 5064, Australia
}

\begin{abstract}
Increased fluctuating asymmetry (FA) of morphological traits occurs under environmental and genomic stress. Such conditions will therefore lead to a reduction in developmental homeostasis. Based upon temperature extreme experiments, relatively severe stress is needed to increase FA under field conditions. Increasing asymmetry tends, therefore, to occur in stressed marginal habitats. Genetic perturbations implying genomic stress include certain specific genes, directional selection, inbreeding, and chromosome balance alterations. It is for these reasons that transgenic organisms may show increased FA. As there is evidence that the effects of genomic and environmental stress are cumulative, organisms in a state of genomic stress may provide sensitive biological monitors of environmental stress.
\end{abstract}

Keywords: asymmetry, homeostasis, metabolic rate, recombination, stress, transgenic organisms.

\section{Introduction}

Phenotypic and genotypic variability tend to be high under conditions of environmental stress (Parsons, 1987; Holloway et al., 1990; Hoffmann \& Parsons, 1991). However, substantial increases in variability occur mainly when stresses are of such severity that there may be injurious changes to a biological system.

Within the first decade of genetic experiments with Drosophila melanogaster, it became established that recombination increases when the temperature at which flies develop is increased or decreased from $25^{\circ} \mathrm{C}$, the normal culture temperature, with major increases close to lethality around 13 and $30^{\circ} \mathrm{C}$ (Plough, 1917). This means that at both high and low temperatures there is a sharp escalation of recombination close to the environmental conditions at which species continuity is threatened. Many later experiments confirm this type of result (Parsons, 1988). Other stresses of common occurrence in nature that increase recombination include starvation in $D$. melanogaster (Neel, 1941).

Experiments with tomatoes show that individuals differ in the extent to which recombination rates are influenced by environmental extremes (Zhuchenko $e t$ al., 1986). In two cold-resistant varieties and in their $F_{1}$ hybrids, reduced temperature did not increase the recombination index which increased in a cold- susceptible variety. In contrast, high temperatures only increased recombination in cold-resistant forms. This is consistent with the view that the effects of environmental perturbations on recombination depend on the degree to which an individual is stressed, which in this case depends on previous stresses to which varieties are adapted.

There is a substantial literature which indicates that structural heterozygosity due to inversions in one part of the genome of D. melanogaster increases recombination in the remainder (Schultz \& Redfield, 1951; Lucchesi \& Suzuki, 1968). In parallel with temperature extremes, the major effect is in the centromeric region with smaller distal increases. Strikingly similar patterns of response have been obtained when heat treatments $\left(12 \mathrm{~h}\right.$ at $\left.35^{\circ} \mathrm{C}\right)$ and interchromosomal effects were investigated simultaneously (Grell, 1978).

In other words, environmental and genomic stresses can have parallel effects upon recombination. This suggests a common underlying mechanism perhaps involving enzymes that control normal pairing (Lucchesi \& Suzuki, 1968). In agreement, there are data which show that genomic and environmental effects on recombination are cumulative in effect (Grell, 1978). Preliminary data in $D$. melanogaster suggest that a relatively mild temperature stress may have substantial effects on a system perturbed by other environmental or genetic variables (Hayman \& Parsons, 1960; Parsons, 1988). 


\section{Fluctuating asymmetry}

Epigenetic processes can be similarly studied following environmental and genetic perturbations. Severe stress applied at certain critical developmental stages can produce abnormal phenotypes so that the variability of development is increased greatly (Waddington, 1956). For population studies, a trait that can be generalized across taxa such as the fluctuating asymmetry (FA) of bilateral characters is having an increasingly important role (Palmer \& Strobeck, 1986). This trait is a measure of developmental stability so that increased FA implies disturbances in developmental homeostasis at the molecular, chromosomal and epigenetic levels (Parsons, 1990a). Both environmental and genomic stresses of sufficiently intense severity should therefore increase FA in a parallel way to recombination.

\section{Environmental stresses}

Examples of increased FA include the following.

1 FA of sternopleural bristle number in adult $D$. melanogaster grown from first instar larvae was substantially greater at $30^{\circ} \mathrm{C}$ than at $25^{\circ} \mathrm{C}$ (Parsons, 1961 , 1962). At $30^{\circ} \mathrm{C}$, which is close to lethality, day-to-day variability was high, as expected because this temperature is so extreme that slight changes in the microenvironment should have a major influence upon developmental stability. In addition, a number of severely abnormal flies at $30^{\circ} \mathrm{C}$ confirmed the poor developmental homeostasis of flies at this temperature. 2 In two species of sand lizard, Lacerta, egg clutches were taken from females from natural populations and the embryos were developed at constant temperatures, $20,25,30$ and $35^{\circ} \mathrm{C}$. Variation of scale characters assessed by FA and the mean numbers of scale disturbances indicated maximum developmental stability at $25^{\circ} \mathrm{C}$ with substantially increased variability both above and below $25^{\circ} \mathrm{C}$ (Zakharov, 1989). The parallel with recombination in D. melanogaster is clear.

3 FA based upon mandibular and maxillary first molars of Wistar rats increased under cold stress, audiogenic stress, and protein deprivation especially when two of the three stresses were combined together (Sciulli et al., 1979). In some cases, litter sizes were reduced, which is a direct indication of a stressful situation that affects a fitness-related trait.

These examples show that FA is useful for monitoring environmental stress. However, relatively severe environmental stress appears necessary to induce significant FA alterations, so that the detection of environmental effects in the field is not simple. One approach is to seek out ecologically marginal situations, for example:

1 for a set of six characters in the butterfly, Coenonympha tullia, Soule \& Baker (1968) found the highest FA at high altitudes in Rocky Mountain populations where the environment can be assumed to be extreme,

2 in the lizard, Lacerta agilis, Zakharov (1989) found the highest FA at the ecological periphery of the range of the species in high mountain populations, and

3 in the introduction of three-spined sticklebacks, Gasterosteus aculeatus, into water bodies in which they have not previously lived, FA increased (Zakharov, 1989).

As FA increases in stressed marginal habitats, it is not surprising that both in the laboratory and in the field, environmental pollutants can increase FA especially in fish (Valentine \& Soulé, 1973; Weiner \& Rago, 1987) but not in all situations. There is a major problem in not knowing the severity of a stress in terms of fitness reductions under field conditions. Furthermore, some chemical stresses may be specific to particular metabolic pathways and may not affect FA (Parsons, 1961, 1990a). Even so, FA does appear to be a useful monitor of environmental stress of such severity that other fitness-related traits may be obviously affected.

\section{Genomic stresses}

Almost any major genetic perturbation, including homozygosity of relatively rare major genes, can be a stress at the genome level by disrupting normal physiological processes whereby destabilizing metabolic excesses and unforeseen phenotypic effects occur. Thus, on evolutionary grounds, fitness is likely to be reduced in genetically perturbed organisms.

Examples of increased FA include the following. 1 Homozygosity of major genes is associated with increased FA in D. melanogaster for bristle mutants (Reeve, 1960), and in the sheep blowfly, Lucilia cuprina, for a diazonin resistance gene using bristle number (Clarke \& McKenzie, 1987).

2 Responses to directional selection in $D$. melanogaster for increased scutellar bristle number were accompanied by a higher FA (Thoday, 1958).

3 Inbreeding in the marine harpacticoid copepod, Tisbe holothuriae, increased the FA of thoracic leg segments (Clarke et al., 1986).

4 In humans, increased dental FA was found in individuals with Down's syndrome (Townsend, 1983).

These and other examples show that major genomic changes including major mutants, responses to selection, inbreeding, and upsetting the balance between chromosomes can increase FA. 


\section{Transgenic organisms}

When nucleic acid molecules are incorporated into cells in the process of forming transgenic organisms, the extra macromolecules imply an energetic cost because of increased synthetic activity associated with a general destabilization of metabolic processes. This is a situation of genomic stress. There are many examples compatible with a fitness cost expressed as an energetic burden in transgenic organisms (Lenski \& Nguyen, 1988). Transgenic pigs with high growth rates have simultaneously a high incidence of gastric ulcers, arthritis, cardiomegaly, dermatitis and renal disease (Pursel et al., 1989). Under the relatively invariant environments contrived by humans such fitness reductions may not be of concern as transgenic organisms are likely to be selected for adaptation and survival undei such conditions.

On exposing transgenic organisms to the variable and stressful environments of nature, this means an energetic cost from a combination of environmental and genomic stresses, so that transgenic organisms may not normally pose a threat on release into natural habitats (Parsons, 1990b). However, transgenic organisms should be sensitive to environmental stresses in nature compared with unmodified organisms, and so should be sensitive monitors of such stress. FA measures of transgenic organisms under benign and stressful environments would therefore be useful in order to test this possibility.

\section{Discussion}

FA is not the only measure of stress. All biochemical pathways are ultimately dependent on the adenine nucleotide path to provide energy. The metabolic energy of cells can be assayed by the adenylate energy charge (Atkinson, 1977). Variations in metabolic rate can be reduced to the adenine nucleotide level, which is important in many reactions of intermediary metabolism. Stress can be regarded as an agent placing an organism at a disadvantage requiring the continued expenditure of excess energy (assessable by metabolic rate) which ultimately threatens survival. An organism can increase its tolerance to a range of environmental stresses by a reduction in metabolic rate, which can occur by genetic or environmental means (Hoffmann \& Parsons, 1991). Conversely high metabolic rate should be associated with stress sensitivity. For example, Root (1990) reports that small birds with high metabolic rates may be promising as monitors of exposure to toxic chemicals.

In D. melanogaster, adults with deleterious behaviourally active mutants such as the 'shakers' are sensitive to temperature extremes and desiccation
(Homyk et al., 1980). Specifically, hyperkinetic, $H k^{1}$, flies have a high metabolic rate, high behavioural activity, reduced longevity, and reduced sensitivity to acrolein stress compared with wild type flies (Trout \& Kaplan, 1970; A. R. Barros et al., personal communication). Preliminary data on longevity reduction on exposure to Los Angeles smog indicate extreme sensitivity to $H k^{1}$ flies, especially when temperature stress is superimposed (Trout \& Hanson, 1971; Parsons, 1991). On energetic grounds, amplifications of the separate effects of stress when in combination are likely (Parsons, 1990c), for example the combination of atmospheric $\mathrm{SO}_{2}$ and $\mathrm{NO}_{2}$ which affect ATP and hence bioenergetic processes (Mansfield \& Freer-Smith, 1981).

Metabolic rate measures are mainly taken from adults, and measures are usually from a particular point in developmental time in an organism. In nature, however, environmental stress affects all life cycle stages especially immature stages which might be quite sensitive to stress; indeed metabolic rates of developing organisms tend to be high. FA in adults is a trait which reflects the total environment during development, and which can monitor the disruption of developmental homeostasis at an array of integration levels from the molecular to the epigenetic. Both the recombination data and the observations on stress-sensitive mutants suggest that detailed FA studies on the effects of combinations of environmental and genomic stresses would be useful for environmental monitoring. From the genetic point of view, the pool of available mutants may be quite substantial as a common consequence of mutants that do not inactivate an enzyme is heatsensitivity of the enzyme (Langridge, 1968), and similarly transgenic organisms could have a role. Incorporating such genetic alterations should permit the detection of stresses of lower intensity than by relying totally upon individuals present in, and adapted to, the environments of natural populations. In this way, careful experimentation could enhance the effectiveness of FA as a biological monitor of stress. Thus, the escalating concern with stress in the environment at large suggests that defining the precise conditions whereby FA increases is an important objective.

\section{Acknowledgements}

I am grateful to Dr G. M. Clarke for alerting me to the work of V. M. Zakharov, and to Dr R. Holst for discussions which indicated that this paper should be written.

\section{References}

ATKInSON, D. E. 1977. Cellular Energy Metabolism and its Regulation. Academic Press, New York. 
ClARKE, G. M., BRAND, G. W. AND WHITTEN, M. J. 1986. Fluctuating asymmetry: a technique for measuring developmenal stress caused by inbreeding. Aust. J. Biol. Sci., 39, 145-153.

CLARKE, G. M. AND MCKENZIE, J. A. 1987. Developmental stability of insecticide resistant phenotypes in blowfly; a result of canalizing selection. Nature, 325, 345-346.

GRELL, R. F. 1978. A comparison of heat and interchromosomal effects on recombination and interference in Drosophila melanogaster. Genetics, 89, 65-77.

HAYMAN, D. L. AND PARSONS, P. A. 1960. The effect of temperature, age and an inversion on recombination values and interference in the X-chromosome of Drosophila melanogaster. Genetica, 32, 74-88.

HOFFMANN, A. A. AND PARSONS, P. A. 1991. Evolutionary Genetics and Environmental Stress. Oxford University Press, Oxford.

HOLLOWAY, G. I., POVEY, S. R. AND SIBLY, R. M. 1990. The effect of new environment on adapted genetic architecture. Heredity, 64, 323-330.

HOMYK, T., SZIDONYA, J. AND SUZUKI, D. T. 1980. Behavioral mutants of Drosophila melanogaster. III. Isolation and mapping of mutations by direct visual observations of behavioral phenotypes. Molec. Gen. Genet., 177, 533-565.

LANGRIDGE, J. 1968. Thermal responses of mutant enzymes and temperature limits to growth. Molec. Gen. Genet., 103, 116-126.

LENSKI, R. E. AND NGUYEN, T. T. 1988. Stability of recombinant DNA and its effect on fitness. Trends Ecol. Evol., 3, 518-520.

LUCCHESI, J. C. AND SUZUKI, D. T. 1968. The interchromosomal control of recombination. Ann. Rev. Genet., 2, 53-86.

MANSFIELD, T. A. AND FREER-SMITH, P. H. 1981. Effects of urban air pollution on plant growth. Biol. Rev., 56, 343-368.

NEEL, J. V. 1941. A relation between larval nutrition and the frequency of crossing over in the third chromosome of Drosophila melanogaster. Genetics, 26, 506-516.

PALMER, A. R. AND STROBECK, C. 1986. Fluctuating asymmetry: measurement, analysis, patterns. Ann. Rev. Ecol. Syst., 17, 391-421.

PARSONS, P. A. 1961. Fly size, emergence time and sternopleural chaeta number in Drosophila. Heredity, 16, 455473.

PARSONS, P. A. 1962. Maternal age and development variability. J. Exp. Biol., 39, 251-260.

PARSONS, P. A. 1987. Evolutionary rates under environmental stress, Evol. Biol., 21, 311-347.

PARSONS, P. A. 1988. Evolutionary rates: effects of stress upon recombination. Biol. J. Linn. Soc., 35, 49-68.

PARSONS, P. A. 1990a. Fluctuating asymmetry: an epigenetic measure of stress. Biol. Rev., 65, 131-145.

PARSONS, P. A. $1990 \mathrm{~b}$. Risks from genetically engineered organisms: energetics and environmental stress. Funct.
Ecol., 4, 265-271.

PARSONS, P. A. 1990c. The metabolic cost of multiple environmental stresses: implications for climatic change and conservation. Trends Ecol. Evol., 5, 315-317.

PARSONS, P. A. 1991. Can atmospheric pollution be monitored from the longevity of stress sensitive behavioural mutants in Drosophila? Func. Ecol., 5, 713-715.

PLOUGH, H. H. 1917. The effect of temperature on crossing over in Drosophila. J. Exp. Zool., 24, 148-209.

PURSEL, V. G., PINKERT, C. A., MILLER, K. F., BOLT, D. J., CAMPELL, R. G., PALMITER, R. D., BRINSTER, R. L. AND HAMMER, R. E. 1989. Genetic engineering of livestock. Science, 224, 12811288.

REEVE, E. C. R. 1960. Some genetic tests on asymmetry of sternopleural chaeta number in Drosophila. Genet. Res., 1, 151-172.

ROOT, M. 1990. Biological monitors of pollution. BioScience, 40, 83-86.

SCHULTZ, J. AND REDFIELD, H. 1951. Interchromosomal effects on crossing over in Drosophila. Cold Spring Harbor Symp. Quant. Biol., 16, 175-197.

SCIULLI, P. W., DOYLE, W. J., KELLEY, C., SIEGEL, P. AND SIEGEL, M. I. 1979. The interaction of stressors in the induction of increased levels of fluctuating asymmetry in the laboratory rat. Am. J. Phys. Anthrop., 65, 279-284.

SOULE, M. AND BAKER, B. 1968. Phenetics of natural populations. IV. The population asymmetry parameter in the butterfly Coenonympha tullia. Heredity, 23, 611-614.

THODAY, J. M. 1958. Homeostasis in a selection experiment. Heredity, 12, 401-415.

TOWNSEND, G. C. 1983. Fluctuating dental asymmetry in Down's syndrome. Aust. Dental J., 28, 39-44.

TROUT, W. E. AND HANSON, G. P. 1971. The effect of Los Angeles smog on the longevity of normal and hyperkinetic Drosophila melanogaster. Genetics, 68, S69.

TROUT, W. E. AND KAPLAN, w. D. 1970. A relation between longevity, metabolic rate, and activity in shaker mutants of Drosophila melanogaster. Exp. Geront., 5, 83-92.

VALENTINE, D. W. AND SOULE, M. 1973. Effect of $p, p^{\prime}$-DDT on developmental stability of pectoral fin rays in the grunion, Leuresthes tenuis. Fish. Bull., 71, 921-930.

WADDINGTON, C. H. 1956. Principles of Embryology, George Allen \& Unwin, London.

WIENER, J. G. AND RAGO, P. J. 1987. A test of fluctuating asymmetry in bluegills (Lepomis macrochirus Rafinesque) as a measure of pH-related stress. Environ. Pollut., 44, $27-36$

ZAKHAROV, V. M. 1989. Future prospects for population phenogenetics. Sov. Sci. Rev. F. Physiol. Gen. Biol., 4, $1-79$.

ZHUCHENKO, A. A., KOROL, A. B., GAVRILENKo, T. A. AND KIBENKO, T. Y. 1986. Correlation between the stability of the genotype and the change in its recombination characteristics under temperature influences. Genetika, 22, 966-974. 